\title{
KONSISTENSI LOGO DALAM MEMBANGUN SISTEM IDENTITAS
}

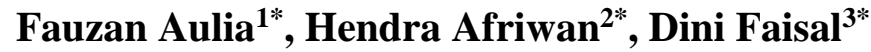 \\ Program Studi Desain Komunikasi Visual Jurusan Seni Rupa Fakultas Bahasa dan Seni \\ Universitas Negeri Padang \\ Jl. Prof. Dr. Hamka, Air Tawar Padang, Kel. Air Tawar Barat, Kec. Padang Utara, Kota Padang, Kode Pos 25137 \\ Sumatera Barat. Indonesia \\ Email:11fauzanaulia@fbs.unp.ac.id, hendrafriwandkv@gmail.com,dinifaisal@fbs.unp.ac.id
}

\begin{abstract}
Abstrak
Penelitian ini bertujuan mengungkap bagaimana pentingnya konsistensi penerapan logo dalam membangun sebuah sistem identitas. Berdasarkan kasus yang diteliti perlu dikaji bagaimana solusi yang akan diperlukan agar sistem identitas terkelola dengan baik. Sehingga diharapkan terjadi persamaan persepsi baik dari pihak internal maupun ekstenal sebuah entitas. Pengelolaan sistem identitas yang baik juga diharapakan memunculkan kesan yang lebih positif. Target pemecahan masalah berdasarkan hasil temuan tersebut adalah mampu menjawab pertanyaan bagaimana menciptakan sebuah standar penerapan logo serta bagaimana pentingnya peran logo sebagai identitas visual. Metode penelitian yang digunakan adalah research and development dengan objek penelitian adalah logo Universitas Negeri Padang. Langkah yang dilakukan adalah sebagai berikut: (1) melacak ragam logo yang muncul dalam penerapannya pada berbagai media di lingkungan kampus UNP, (2) mengukur tingkat pemahaman civitas akademika UNP tetang tentang logo UNP, dan (3) menetapkan solusi dari permasalahan yang muncul berupa rancangan guideline logo Universitas Negeri Padang sebagai acuan standar pengaplikasian logo. Hasil penelitian ini adalah berupa fakta di lapangan tentang penerapan logo UNP di lingkungan kampus UNP, tingkat pemahaman civitas akademika UNP tentang logo UNP dan produk berupa Standart Manual Guideline penerapan logo UNP sebagai solusi dari permasalahan yang ditemukan.
\end{abstract}

Kata Kunci: konsistensi, identitas visual, logo.

\begin{abstract}
This study aims to reveal how the importance of consistent logo application in building an identity system. Based on the case studied, it is necessary to study how the solution will be needed so that the identity system is managed properly. So it is expected that there will be a common perception of both internal and external parties of an entity. It is also hoped that a good management of the identity system will create a more positive impression. The target of solving the problem based on these findings is to be able to answer the question of how to create a standard for implementing a logo and how important the role of the logo is as a visual identity. The research method used is research and development with the research subject being the Padang State University logo. The steps taken are as follows: (1) tracking the various logos that appear in their application to various media in the UNP campus environment, (2) measuring the level of understanding of the UNP academic community about the UNP logo, and (3) determining solutions to problems that arise in the form of Padang State University logo guideline design as a standard reference for logo application. The results of this study are in the form of facts in the field about the application of the UNP logo in the UNP campus environment, the level of understanding of the UNP academic community about the UNP logo and products in the form of a Standard Manual Guideline for the application of the UNP logo as a solution to the problems found.
\end{abstract}

Keywords: consistency, visual identity, logo.

\section{PENDAHULUAN}

Peran penting identitas adalah sebagai pembeda atau penanda pada suatu hal yang melekat pada suatu objek. Adanya identitas membuat kita bisa membedakan, mengidentifikasi, dan mengenali suatu objek atau yang mewakilinya. Dianalogikan pada personal seseorang yang memiliki identitas berupa nama, tanda-tanda fisik (bentuk wajah, postur tubuh, dll), atau ciri khas lainnya yang bisa membuat seseorang dapat teridentifikai dan dikenali dari ciri khas yang muncul tersebut. Hal tersebut merupakan gambaran bagaimana peran atau fungsi identitas. Logo merupakan bagian dari identitas visual dan salah satu bentuk identitas pada sebuah entitas. Entitas dapat berupa perusahaan, instansi, organisasi, atau komunitas tertentu. 
Terkait ulasan sebelumnya, penelitian ini mengungkap permasalahan identitas visual Universitas Negeri Padang dan solusi yang digagas. Peneliti mimiliki alasan mengapa permasalahan identitas visual Universitas Negeri Padang perlu dikaji. Diantaranya adalah (1)temuan beberapa macam bentuk logo Universitas Negeri Padang. Perbedaan terlihat dari beberapa ragam bentuk logo Universitas Negeri Padang yang muncul tidak terlalu signifikan, namun jika dikaji dari sudut pandang desain komunikasi visual hal tersebut menjadi masalah. (2)Pengamatan selanjutnya tekait warna dan jenis font yang merupakan bagian dari logo tidak konsisten. (3)Selain itu juga ditemukan penerapan logo Universitas Negeri Padang pada berbagai media yang tidak konsisten.

Penelitian ini bertujuan mengungkap bagaimana pentingnya konsistensi penerapan logo dalam membangun sistem identitas. Dalam hal ini penerapan logo UNP pada berbagai media di lingkungan kampus UNP menjadi objek penelitian. Hal selanjutnya adalah mengungkap fakta bahwa terdapat beberapa ragam logo UNP yang muncul baik di dunia maya maupun yang ditemukan pada berbagai media cetak. Kemudian berdasarkan hasil temuan tersebut akan dikaji bagaimana solusi yang akan diperlukan agar sistem identitas UNP terkelola dengan baik. Sehingga diharapkan terjadi persamaan persepsi baik dari pihak internal maupun ekstenal. Pengelolaan sistem identitas yang baik juga diharapakan memeunculkan kesan yang lebih positif. Target pemecahan masalah berdasarkan hasil temuan tersebut adalah mampu menjawab pertanyaan bagaimana standar logo Universitas Negeri Padang yang sesungguhnya, serta bagaimana pentingnya peran logo sebagai identitas visual.

\section{KAJIAN TEORI}

\section{Semiotika}

Semiotika atau ilmu yang membahas tentang tanda merupakan salah satu alat bedah yang juga digunakan dalam bidang komunikasi visual. Semiotika mengkaji tentang bagaimana sebuah tanda diciptakan dan diinterpretasi oleh pengguna tanda. Semiotika merupakan ilmu atau metode analisis untuk mengkaji tanda. Tanda-tanda adalah perangkat yang dipakai dalam upaya berusaha mencari jalan di dunia ini, di tengah-tengah manusia dan bersama-sama manusia (Sobur, 2013:15).

Kajian semiotika dibutuhkan dalam memahami acuan dalam proses pembentukan tanda sebagai identitas maupun dalam mengkaji visual identity yang terdapat pada suatu entitas. Penggunaan tanda dalam berkomunikasi ditemui pada berbagai hal. Pada umumnya tanda mengandung 2 (dua) bentuk. Pertama tanda menjelaskan (baik secara langsung maupun tidak langsung) tentang sesuatu dengan makna tertentu. Kedua, tanda mengkomunikasikan maksud suatu makna. Hal ini terjadi pada sistem identitas suatu entitas. Salah satu bentuk identitas tersebut adalah logo. Fungsi logo sebagai sebuah tanda membutuhkan konsistensi agar proses identifikasi dan transfer makna terwujud dengan baik.

Produksi tanda dan pemahaman makna atas sebuah tanda akan terjadi dengan baik pada kelompok tertentu yang memiliki suatu latar belakang pengetahuan yang sama sehingga dapat menciptakan suatu pemahaman yang (hampir) sama (Stuart Hall, 2003) Pandangan Pirce terhadapat semiotika mengungkapkan bagaimana transfer makna terjadi melalui sebuah tanda oleh interpretan. Sebuah tanda mengacu pada sesuatu di luar dirinya sendiri atau suatu objek yang mewakilinya. Tanda yang dipahami oleh seseorang akan memiliki efek di benak penggunanya atau interpretan. Interpretan yang dapat memahami sebuah tanda harus memiliki latar belakang pengetahuan tentang objek atau tanda yang dilihat. Sehingga proses identifikasi terhadap suatu tanda dan makna dapat berjalan.

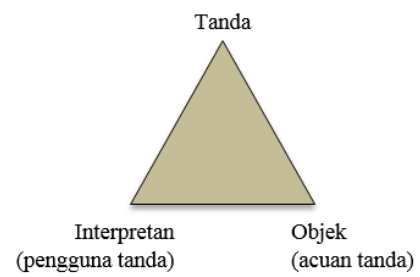

Gambar 1. Unsur makna menurut Pierce

\section{Logo}

Perkembangan pengetahuan tentang sistem identitas visual, membuat kesadaran bahwa aspek non fisik (value, reputasi, kualitas, makna, dll) terkait erat dengan aspek fisik sebagai penanda. Visual identity atau identitas visual mencakup segala bentuk aset visual yang akan dikenali oleh masyarakat ketika sebuah brand muncul ke permukaan. Salah satu elemen identitas merek yang biasa digunakan secara global sebagai penanda adalah logo (Simonson and Schmitt 1997; Lans et al. 2010). Hal ini dikaitkan dengan logo UNP sebagai penanda yang berfungsi sebagai identitas yang berwujud fisik dan merupakan aset visual.

Brand dari segi wujudnya bersifat fisik dan bersifat non fisik (Rustan, 2021). Dari wujud fisik berupa nama, logo, warna, tipografi dan bentuk aset grafis lainnya. Sedangkan wujud non fisik berupa kesan, velue, reputasi yang dimiliki atau penilaian publik. Sehingga keterkaitan logo dan bentuk identitas lainnya dengan 
Gorga : Jurnal Seni Rupa

Volume 10 Nomor 02 Juli-Desember 2021

p-ISSN: 2301-5942 | e-ISSN: 2580-2380

brand sangat erat dan saling menunjang. Logo digunakan sebagai alat komunikasi yang membentuk identitas dari suatu perusahaan, lembaga, maupun produk. Identitas Visual sering digunakan untuk membedakan antar produk/jasa yang bersaing sehingga costumer akan dengan mudah mengenal suatu merek hanya dengan melihat sebagian dari tampilan visualnya. Logo merupakan atribut utama suatu entitas yang terlihat secara fisik mewakili sebuah nilai.

Pemahaman tentang logo dapat dipahami bahwa logo adalah sebagai sebuah lambang baik dalam bentuk visual berupa gambar maupun tulisan. Pada sebuah logo terdapat nilai estetika dan makna tertentu guna mengkomunikasikan sisi positif dan sosok dari sebuah entitas. Entitas tersebut bisa saja bergerak di bidang produk maupun jasa, atau instansi. Hal ini menjelaskan fungsi logo merepresentasikan nilai dan visi dari penggunanya melalui berbagai elemen-elemen yang ada pada sebuah logo.

Sebuah logo terdapat elemen dasar sebagai form generator sebuah bentuk atau rupa. Form generator tersebut meliputi poin, garis, bidang, dan volume. Kemudian selain dasar pembentuk rupa tersebut, terdapat atribut yang berfungsi sebagai pengatur ukuran, gaya/style posisi, arah, jumlah, jarak, warna, tekstur dan lain-lain. Atribut merupakan tata kelola elemen-elemen dasar pembentuk rupa. Hal ini sama halnya dengan prinsip-prinsip layout (emphasis, sequence, balance, dan unity). Elemen-elemen dasar yang telah membentuk sebuah rupa dan ditata sedemikian rupa akan menggiring sebuah persepsi bagi yang melihat atas rupa yang tampak tersebut. Kemudian muncul interpretasi atau tafsiran makna atas rupa yang dilihat. Proses tersebut merupakan gambaran bagaimana sebuah logo dirancang mampu membentuk interpretasi.

Representasi visi dan misi dari sebuah entitas harus terwakilkan melalui logo, segmentasi yang dituju sesuai target kepada masyarakat. Fungsinya sebagai penanda agar mudah diingat dan dikenali oleh khalayak yang dirancang dengan menarik dan sederhana (Katz dalam Wheeler, 2009). Istilah logo sudah sering didengar merupakan istilah yang berasal bahasa yunani yang berarti pikiran, pembicaraan, akal budi. Istilah "logotype" lebih dulu popular sebelum istilah "logo" (Rustan, 2017). Awalnya logotype sebagai tulisan nama entitas yang muncul tahun 1810-1840 dengan menggunakan teknik lattering atau memakai jenis huruf tertentu. Sehingga logotype adalah elemen tulisan saja. Perkembangan logotype semakin unik/berbeda satu sama lain yaitu dengan menambahkan elemen gambar sehingga tulisan dan gambar berbaur menjadi satu.

Anatomi sebuah logo umumnya ada yang terdiri dari 2 elemen yaitu gambar dan tulisan, ada yang terdiri dari 1 elemen tulisan saja, ada yang terdiri dari elemen gambar saja, dan ada juga terdiri dari gambar dan tulisan yang berbaur. Bagaimanpun konsepnya desainer harus mampu merancang sebuah logo yang unik dan berbeda sesuai dengan fungsinya sebagai penanda atau pembeda dengan kompertitornya.

\section{Standard Manual Guidelines}

Standard Manual Guideline berisi informasi tentang segala bentuk identitas termasuk logo, merek, identitas warna dan lain-lain baik secara internal kepada organisasi atau bisnis, serta secara eksternal kepada mitra, afiliasi, dan masyarakat umum. Standard Manual Guideline berisi bagian tentang identitas meliputi misi, nilai inti, kepribadian, nada, elevator pitch, dll. Kemudian aset identitas visual dan penggunaan yang sesuai, aset tersebut beupa logo, palet warna, jenis huruf, spasi, latar belakang, dll.) Standard Manual Guideline adalah sumber daya yang sangat berguna saat melakukan branding ulang atau pemula sebagai cara berkomunikasi dengan khalayak. Terkait dengan identitas visual UNP, Standard Manual Guidelines diharapkan mampu menjadi pemicu penyatuan persepsi dan mewujudkan konsistensi suatu identitas.

\section{METODE PENELITIAN}

Secara garis besar ada 2 tahapan dalam penelitian ini, yaitu: (1) melacak ragam logo Universitas Negeri Padang yang muncul dalam pengaplikasiannya pada berbagai media. Pelacakan akan dilakukan dengan observasi langsung ke lapangan dan penelusuran melalui dunia maya atau internet. (2) Studi pelacakan ragam logo UNP yang muncul disertai dengan mengukur tingkat pemahaman civitas akademika UNP tentang logo UNP. Hal ini untuk menguatkan alasan perlunya hal dikaji dari segi ilmu desain komunikasi visual dan perlunya hal ini untuk menjadi perhatian oleh civitas akademika UNP.

Langkah berikutnya adalah (3) merancang solusi berupa guideline logo Universitas Negeri Padang sebagai acuan standar logo. Berdasarkan 2 langkah tersebut metode penelitian yang digunakan adalah research and development (R\&D) yang memiliki beberapa tahapan atau proses pengembangan dari hasil riset permasalahan yang dikaji. Tahapan tersebut dimulai dengan mengamati potensi dan masalah yang terjadi, mengumpulkn informasi, desain, validasi 


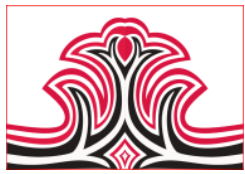

desain, revisi desain, uji coba produk, revisi produk dan produksi produk.

\section{HASIL DAN PEMBAHASAN \\ 1.Hasil}

Hasil penelitian menemukan fakta visual berupa bentuk logo yang terdapat pada berbagai media informasi di lingkungan kampus Universitas Negeri Padang. Berdasarkan hasil studi pelacakan yang dilakukan di lingkungan kampus UNP, meliputi kampus I,II, III, IV dan V ditemukan logo-logo UNP yang tidak konsisten dan teraplikasi di berbagai media. Seperti pada plangplang nama jurusan, fakultas, pascasarjana dan sarana lainnya yang ada di lingkungan kampus UNP. Hal ini dibuktikan berdasarkan pantauan langsung ke lapangan tentang bagaimana penggunaan atau pengaplikasian logo UNP tersebut.

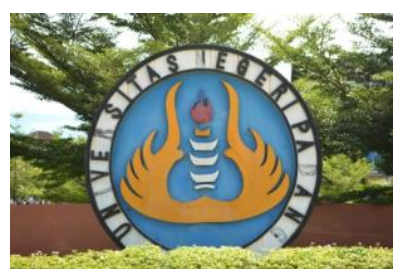

Gambar 2. Penggunaan Logo di Depan Rektorat UNP

Jika dibandingkan penggunaan logo yang berada pada landmark yang berada di depan rektorat UNP, terlihat perbedaan dengan bentuk logo yang digunakan pada Laboratorium Gambar di Jurusan Teknik Sipil FT UNP. Hal ini tidak terjadi diantara tempat tersebut, terdapat juga perbedaa-perbedaan logo yang digunakan seperti pada plang jurusan yang ada di kampus UNP. Begitu juga pada media-media informasi lainnya yang berada di lingkungan kampus UNP.

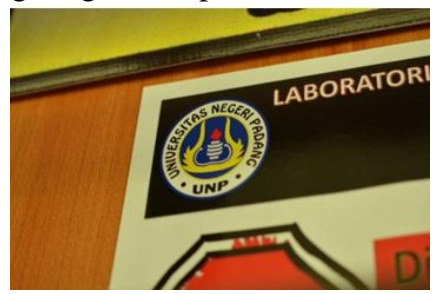

Gambar 3. Penggunaan Logo UNP pada Laboratorium Gambar di Jurusan Teknil Sipil

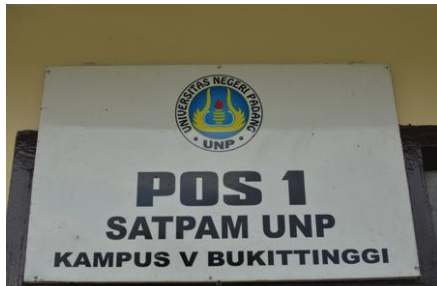

Gambar 4. Pengguanaan Logo UNP di Pos Satpam Kampus V UNP

Hasil penelusuran melalui internet, juga ditemukan beberapa bentuk logo yang serupa namun tidak sama.
Gorga : Jurnal Seni Rupa

Volume 10 Nomor 02 Juli-Desember 2021

p-ISSN: 2301-5942 | e-ISSN: 2580-2380

Perbedaan dapat terlihat dari sisi warna, proporsi bentuk, penggunaan font.

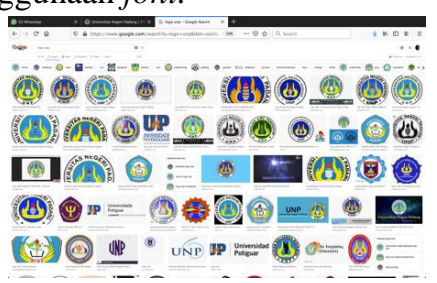

Gambar 5. Penelusuran Logo Melalui Google

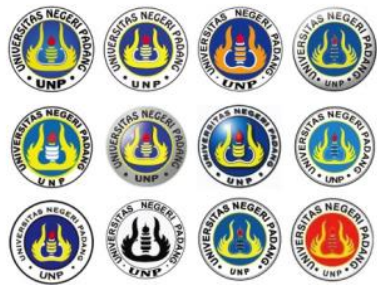

Gambar 6. Temuan Bentuk-Bentuk Logo Unp dari Internet

Potensi permasalah yang muncul tersebut, peneliti juga mengukur tingkat pemahaman civitas akademika UNP, peneliti mencoba menyebar kuesioner kepada civitas akademika UNP meliputi dosen, tenaga kependidikan, dan mahasiswa. Salah satu pertanyaan dalam kuesioner tersebut yang berisi pertanyaan tentang bagaimana bentuk logo UNP yang benar menurut pendapat pribadi. Kuesioner tersebut memberikan 5 opsi bentuk logo UNP yang dapat dipilih, dimana salah satu logo tersebut merupakan logo yang ditetapkan berdasarkan Statuta UNP. Logo yang dijadikan opsi dalam kuesioner tersebut terdiri dari 5 opsi diantaranya:

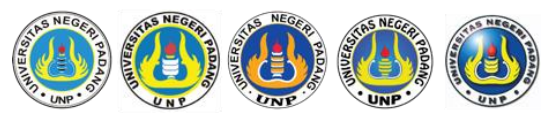

Gambar 7. Opsi Logo yang Dimunculkan dalam Kuesioner (Opsi $1,2,3,4$ dan 5)

Hasil yang diperoleh melalui kuesioner tersebut, dari 154 partisipan 42,9\% menjawab opsi ke-3, 35,7\% menjawab opsi yang ke 2, 15,6\% memilih opsi ke-1, $4,5 \%$ memilih opsi ke-4, dan 1,3\% opsi yang ke-5.

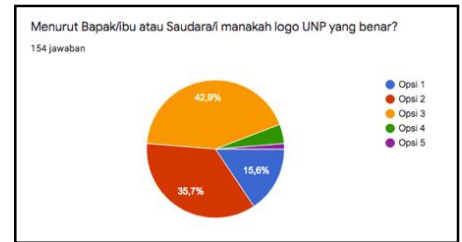

Gambar 8. Persentase Jawaban pada Kuesioner

Persentase jawaban dari kuesioner di atas mengindikasikan persepsi civitas akademika UNP tentang logo UNP tidak sama. Hal ini memberi penguatan terhadap alasan pentingnya dilakukan sosialisasi dan pemahaman tentang logo UNP yang ditetapkan dalam statuta UNP serta pengawasan pihak tertentu tentang pengaplikasian logo UNP pada 
berbagai media.

\section{Pembahasan}

Berdasarkan hasil penelitian yang telah dijabarkan sebelumnya, dapat dilihat hal-hal yang diakibatkan oleh pengelolaan sistem identitas yang kurang maksimal. Sebagai contoh pengelolaan sistem identitas, hal ini dibandingkan dengan pengelolaan identitas visual seperti yang dilakukan oleh Universitas Gadjah Mada dan Universitas Indonesia. Hal ini terlihat pada cara pengelolaan elemen-elemen logo, komposisi, dan pengaturan standar penerapan logo.

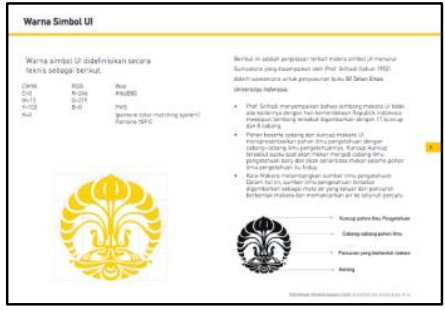

Gambar 9. Contoh Standarisasi Logo Universitas Indonesia (UI)

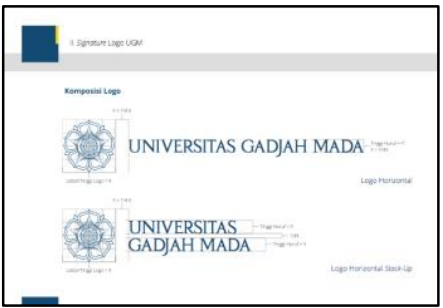

Gambar 10. Contoh Standarisasi Komposisi Logo UGM

Standarisasi yang dilakukan Universitas Indonesia dan Universitas Gadjah Mada tersebut menjadi acuan perbandingan agar pengelolaan identitas visual Universitas Negeri Padang lebih maksimal. Kemuadian hal tersebut diharapkan menjadi solusi terhadap permasalahan konsistensi identitas visual Universitas Negeri Padang (UNP).

Berdasarkan penelusuran tentang aturan bentuk logo UNP telah diatur dalam Peraturan Menteri Riset, Teknologi, dan Pendidikan Tinggi Republik Indonesia, Nomor 67 Tahun 2016 tentang Statuta Universitas Negeri Padang. Pada Bab II bagian kedua, Pasal 3, 4, dan 5 yang berisi tentang ketetapan visual logo secara keseluruhan, warna, dan makna lambang UNP. Berdasarkan pengamatan, aturan tersebut tidak dilanjutkan dengan penjelasan yang lebih detail tentang proporsi bentuk, komposisi, ukuran dan aturan pengaplikasian logo UNP. Begitu juga jenis font yang digunakan tidak ada ketetapannya. Hal ini tampak hanya pembakuan secara konsep atau makna dari logo yang berperan sebagai identitas. Dari sisi visualisasi pembakuannya masih sangat lemah karena tidak terdapat pembakuan proporsi maupun komposisi seperti contoh perbandingan pengelolaan identitas visual UI dan UGM.

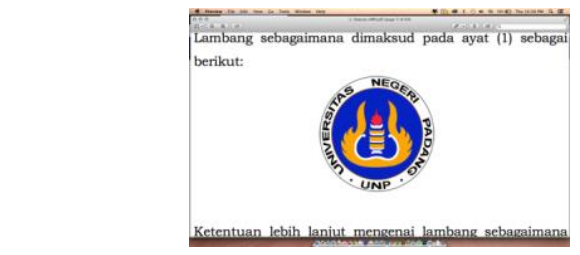

Gambar 11. Capture visualisi bentuk logo yang ditampilakn pada Statuta UNP

Penggunaan logo pada berbagai media informasi yang ada di lingkungan kampus UNP tidak merujuk pada Statuta UNP. Berdasarkan temuan-temuan fakta logo UNP yang bervariasi, tingkat pemahaman civitas akdemika UNP dan faktor penyebab tidak konsistennya penggunaan logo UNP di lingkungan kampus UNP dibutuhkan ide/gagasan sebagai problem solving menindaklanjuti permasalahan-permasalahan yang telah diuraikan sebelumnya. Solusi yang akan diambil adalah merancang standard manual guideline yang berisi tentang:

1. Aturan tertulis tentang ketetapan logo UNP menurut Statuta UNP mengenai bentuk, makna, dan warna logo UNP (berdasarkan Statuta UNP).

2. Memperbaiki standarisasi bentuk logo UNP dengan grid system merujuk pada logo yang direkomendasikan dalam Statuta UNP. Dalam hal ini tidak merubah bentuk logo melainkan menyempurnakan bentuk dan membakukan pola logo UNP agar lebih simetris dan teratur.

3. Aturan penerapan logo UNP pada berbagai media.

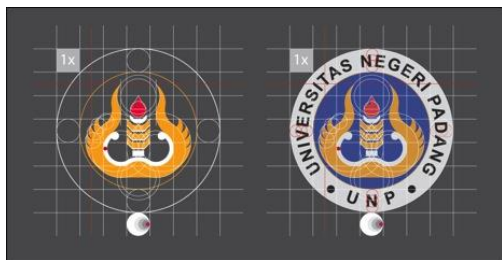

Gambar 12. Hasil Rekonstruksi menggunakan Sistem Grid

Pembakuan bentuk ini diharapkan menjadi standar konstruksi logo sehingga proporsi bentuk logo UNP terjaga. Hal ini merupakan solusi yang ditawarkan dari permasalahan yang telah diuraikan sebelumnya. Lebih lengkapnya standard manual guideline ini disusun dalam bentuk buku panduan berbasis cetak dan juga digital yang bisa diakses apabila ditempatkan pada website resmi institusi. Selain itu juga diperlukan tempat khusus atau link khusus untuk men-download file logo UNP yang bisa diakses civitas akademika UNP maupun masyarakat sebagai logo yang benarbenar resmi. Sehingga dengan sumber yang jelas tersebut diharapakan konsistensi penggunaan logo 


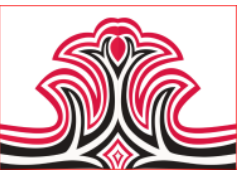

UNP akan terwujud.

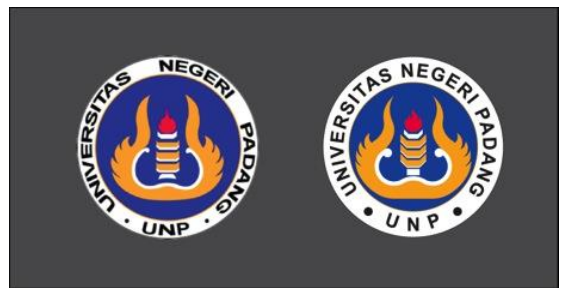

Gambar 13. Perbandingan Visualisasi Logo UNP pada Statuta (Kiri) dengan Logo yang Telah Direkonstruksi (Kanan)

\section{KESIMPULAN DAN SARAN}

\section{Kesimpulan}

Penyebab terjadinya pengaplikasian logo yang berbeda-beda di lapangan dapat disimpulkan karena beberapa faktor berikut ini: 1). Aturan tentang logo yang telah ditetapkan dalam Statuta UNP kurang dipahami dan tersosialisasi dengan baik di lingkungan civitas akademika UNP. 2). Aturan logo UNP yang telah ditetapkan dalam Statuta UNP tidak begitu detail menjelaskan bagaimana aturan bentuk logo, seperti penggunaan font, proporsi logo, aturan penerapan logo. 3). Penggunaan logo tidak merujuk pada statuta UNP tentang aturan bentuk logo UNP. 4). Tidak tersedia tempat khusus untuk mengunduh logo yang sesuai dengan ketetapan Statuta UNP pada website atau media lainnya. 5). Tidak ada pengawasan pihak terkait tentang penerapan logo.

\section{Saran}

Berdasarkan temuan-temuan di lapangan tentang konsistensi identitas visual terdapat beberapa hal yang perlu diperhatikan dalam membangun sistem identitas. Selain aturan yang telah ditetapkan oleh undangundang diperlukan pendukung lainnya dalam proses bagaimana sebuah identitas mampu berfungsi dengan maksimal. Berdasarkan penelitian, hal yang dapat dilakukan dalam membangun sistem identitas khusunya pada kasus konsistensi identititas visual UNP sebagai berikut: 1). Konsistensi penerapan logo UNP perlu diawasi melalui manual guidelines yang diharapkan mampu membentuk interpretasi bagi civitas akademika UNP, 2). Menyediakan tempat pengunduhan yang resmi logo beserta manual gidelines sehingga diharapkan adanya kemudahan akses informasi tentang identitas visual UNP, dan 3). Melakukan sosialisasi tentang aturan penerapan logo di lingkungan kampus UNP sebagai upaya menyatukan persepsi baik civitas akademika UNP maupun masyarakat luas tentang identitas UNP.

\section{UCAPAN TERIMA KASIH/ PENGHARGAAN}

Peneliti menyampaikan penghargaan yang tinggi dan terima kasih kepada Lembaga Penelitian dan
Gorga : Jurnal Seni Rupa

Volume 10 Nomor 02 Juli-Desember 2021 p-ISSN: 2301-5942 | e-ISSN: 2580-2380

Pengabdian Masyarakat Universitas Negeri Padang yang telah membiayai penelitian ini dengan nomor kontrak penelitian : 613/UN35.13/LT/2021.

\section{DAFTAR RUJUKAN}

Bintarto, J., Jhon, J., \& Purba, R. (2016). Kajian Semiotika Pada Logo Sanggar Reog Singo Barong Kabupaten Langkat. PROPORSI: Jurnal Desain, Multimedia dan Industri Kreatif, 2(1), $69-77$.

Brand UGM. (2021). Mengapa Menggunakan Panduan Ini. https://brand.ugm.ac.id/brand-guideline/ (diakses 30 Desember 2021).

Dewi, T. P. C., Bramantijo, B., \& Sutanto, R. P. (2013). Redesain Logo dan Perancangan Corporate Identity Roemah Wangi Salon dan Spa di Malang. Jurnal DKV Adiwarna, 1(2), 11.

Everlin, S., \& Erlyana, Y. (2020). Analisis Perubahan Desain Logo Gojek Tahun 2019. DESKOMVIS: Jurnal Ilmiah Desain Komunikasi Visual, Seni Rupa dan Media, $1(1), 72-88$.

Januariyansah, S. (2018). Analisis Desain Logo Berdasarkan Teori: Efektif Dan Efisien. Yogyakarta: Universitas Negeri Yogyakarta.

Nugraha, A. R. (2016). Representasi corporate identity dalam logo baru pdam kota bandung. Communication, 7(2), 26-44.

Rustan, Suriato. (2017). Mendesain Logo. Jakarta: Gramedia Pustaka Utama.

Rustan, Suriato. (2021). Logo 2021 Buku 1. Jakarta: CV Nulisbuku Jendela Dunia.

Rustan, Suriato. (2021). Logo 2021 Buku 2. Jakarta: CV Nulisbuku Jendela Dunia.

Sugiyono. (2016). Metode Penelitian Kuantitatif, Kualitatif, dan $R \& D$. Bandung: Alfabeta.

Sultanatta, C., \& Maryam, S. (2019). Analisis Semiotika Logo Brodo Footweardi Media Sosial Twitter (Studi Analisis Semiotika Roland Barthes). EKSPRESI DAN PERSEPSI: JURNAL ILMU KOMUNIKASI, l(1).

UI. (2021). Identitas Tentang UI. https://www.ui.ac.id/tentang-ui/identitas.html (diakses 30 Desember 2021).

UNP. (2021). Peraturan Menteri Riset, Teknologi, dan Pendidikan Tinggi Republik Indonesia. https://www.unp.ac.id/patch/document/a1f2a d229646b138abb6a7f2c61672cf.pdf (diakses 30 Desember 2021).

Wheeler, A. (2009). Designing Brand Identity: An Essential Guide for the Entrrie Branding Team. New Jersey: John Wiley \& Sons, Inc. 